ISSN 1112-9867

Available online at

http://www.jfas.info

\title{
IDENTIFYING INTELLIGENT BUILDING MANAGEMENT SYSTEMS (BMS) IN SUSTAINABLE HOUSING
}

\author{
S. K. Mirpadiab ${ }^{1}$, S. Bagheri ${ }^{2}$ \\ ${ }^{1}$ Architecture, energy, technology and architecture research, a member of landscape \\ architecture Iranian Scientific Society \\ ${ }^{2}$ Master of Architecture, Islamic Azad University of Yazd
}

Published online: 15 May 2016

\begin{abstract}
Today, one of the things that have been the basis for most architects and design experts is paying attention to the principles of sustainability of energy and organized approach to sustainable development. If sustainability be reflected in the energy sector, it must be coordinated with other aspects such as social sustainability. There are always architects who define sustainability based on their view, but this study is trying to be formed on theoretical basis of architectural energy experts, and according to available resources and access to library studies in the field of technology BMS, introduce this technology to the people who are concerned about it. So that by this technology be an important factor in achieving sustainability in architecture.
\end{abstract}

Keywords: Building Automation, Intelligent Management, Sustainable Architecture, Building Management Systems (BMS) In Housing

Author Correspondence, e-mail: author@ gmail.com

doi: http://dx.doi.org/10.4314/jfas.v8i3s.247

\section{INTRODUCTION}

One of the most important issues in recent decades that were interesting for developed industrial countries is wasting energy. Developing countries access to new sources of energy, 
which is crucial for their economic development and new researches have shown that there is a direct relationship between the level of development of a country and its energy consumption. In Iran because of the abundance of fossil energy sources, little action has been taken in this regard. Paying attention to the architecture of the building is one of the principles that our country should be examined. According properly designed and taking into account the climate and energy, is guarantying building occupants comfort. Energy efficiency and use of renewable energy sources is something that should be of interest to architects and designers. Given the limited reserves of fossil resources can no longer be relied upon and should benefit from renewable energy. We are currently on the verge of the next generation of buildings. Buildings that are able to take advantage of new technology intelligently adapt to suit their interests. Intelligent design can be used with different systems to manage energy consumption in buildings and minimize it. Intelligent Building Integrated Management System refers to a system with which it is sought using the latest technology and energy efficiency in buildings and creates ideal conditions. The goal of implementing intelligent building components is functioning according to the circumstances and needs of the building at the time. Implementing intelligent building is saving time, labor and costs. Compared with traditional buildings can significantly reduce energy and provide communication and security facilities. New buildings should be applicable to any possible changes.

\section{DEFINITIONS}

\subsection{Sustainable Architecture}

Green architecture or sustainable architecture is a new trends architecture derived from the concepts of sustainable development. The purpose of creating green buildings is improving weather, stop wasting energy and consumption and also reducing negative effects of construction on the environment. To achieve human comfort, strategies should be considered to help security and comfort that can be provided. One of these strategies is to use solar energy, wind, thermal and daylight. Intelligent building and green building does not have the same meanings but they overlap each other. 


\subsection{Intelligent building}

Since the bulk of the country's total energy consumption is in the building sector and the use of energy management systems makes planning in energy consumption and thus save and optimize energy consumption and costs as well as reducing power consumption significantly, yet it has proper interaction with the environment. Creating sustainable architecture and in harmony with the climate, is one of the goals of designers and builders of intelligent buildings (Seyedian et al).

Today, buildings are kind of technology. They adapt themselves with technology and benefit from it. A smart building increase performance and efficiency of its inhabitants and the possibility of effective management in accordance with specific requirements and provide the lowest cost (Afshari Basir et al, 2011). Perhaps the first achievements of intelligent building, compared with traditional buildings is optimizing energy consumption, lower maintenance costs and better services and security services, as well as ease of design, and the satisfaction of the residents (alphaworks.ibm.com).

\subsection{General definition of Intelligent Building:}

Defining the responsibilities of the position and the selection of materials in new structure

Defining and synthesize information infrastructure buildings

Flexible and scalable for network systems

The combination of sound and management for energy systems

\subsection{Building Management Systems (BMS)}

Intelligent management system or automation in building not only spans in application and it's literally usage, but also many researchers taunted this vision and by generalizing many definitions that can be achieved and studied. Intelligent Building Management System refers to a set of hardware and software which is installed in the building in order to integrated monitoring and controls the vital parts. The task of continuous monitoring of the various parts of the building and commands applied to them so that performance of building components interact with each other and in optimal conditions and with the aim of reducing unwanted applications and allocation of energy resources is only for spaces during operation (Industrial Designer 2010). Artificial Intelligence in the construction industry in Iran is a 
comprehensive system of intelligent building management system that is known to control planting intelligent equipment management of mechanical, electrical and electronic which is used in any buildings. In fact by using a set of electronic components in each building, in any dimensions the indicators of consumption, energy costs, maintenance, passive defense crisis, remote control, safety and security and environmental effects can be managed (Sarmadi, 2013). In a simple definition it can be said that intelligent building refers to a building that equipped with modern information and communication systems so that the building to be able to take advantage of an intelligent central system to record every minute changes and coordinate and adapt with new conditions and surroundings. A more comprehensive definition of intelligent building is technology-based innovation in the form of a combination of intelligent management and in order to know how to return the investment (Behzadi, 2004). By using a variety of sensory sensors inside and outside the building with the use of a single network we can be aware of permanent and real time information system temperature, pressure, humidity, air flow, the amount of oxygen available to the carbon dioxide and use them in order to achieve ideal conditions (Kamarposhti, 2011). One of the ways to optimize energy consumption is using intelligent building management system (BMS) (Rezaei et al, $2013 ; 10)$. In building management system many of the habit of inhabitants which are doing involuntarily can be done by intelligent a system, which saves time and cost of labor and follows by reducing energy consumption, energy costs, fallibility and increase the effectiveness of the system. Or by using sensors inside and outside the building or the use of a single system can be used in real-time, control all the comfort and security and use them in order to achieve ideal conditions. For this purpose, it requires specific hardware and software equipment that environmental data collection and transfer of data to the central system, and process control and building management implemented (Hariri, 2009). In this type of system by installing sensors of temperature measurement, opening and closing doors and the windows, detect the presence and movement of people and the amount of ambient lighting, and measure the environmental conditions and to reduce consumption and increase environmental quality to give appropriate commands to the air conditioning system and lighting issue (Rezaei et al, 2013; 10). Building management system (BMS) or building 
automation system (BAS) system that is installed in a building and make possible for the user to control different parts of the building through suitable component outputs. Different parts of control systems usually include mechanical ventilation (HVAC) equipment and lighting, which can accelerate safety systems, fire protection, set permissions, and uninterruptible power supply (Morovati et al, 2014; 3). Total use of information technology in building automation, building management that is in line with its product dynamic system, safe and useful that helps integration of building management. To reduce the cost of construction and optimal use of technology development of communications technology and computer and performance of management systems building automation are impressive that cover total energy savings so that the savings resulting from using these systems within a short time would compensate the offset costs (Kamarposhti et al, 2011: 428). Generally the objective of the BMS systems in a building due to environmental conditions is the need to adapt the operating conditions of the various components of the building at the time (Morovati et al, 2013:3). Intelligent control systems will be flexible, that can be easily adapted to different needs. Also during operation they can be easily changed and optimized operations for better governance and reduce energy costs and reduce maintenance costs. The building automation in addition to provide control and facility planning household appliances from anywhere inside or outside the home, make you aware of internal condition. Also, in spite home automation, smart building are responsible for energy management, heating and cooling system (HVAC), lighting, traffic control and safety, fire leads many details of the house that never imagined it would be automatic (Kamarposhti et al, 2011: 428). BMS is responsible for the the central processing refers to a system by which the requirements of a building automation and automatically people with minimal interference, control and manage. Due to the use of intelligent and non-intelligent systems in buildings built in our country, that usually operate in isolation from each other is proposed that first this approach at the facility and mechanical equipment, including cooling systems, heating and air conditioning become common, in addition to its benefits, including the following are the main beneficiary, the state and the entire country and even future generations: 1- Reducing negative environmental impacts during operation of the building 2- Reducing energy consumption and costs 3- 
Optimal maintenance of facilities and equipment, mechanical, electromechanical, electrical and electronical 4- Effective in passive defense and crisis management 5- Enabling remote control 6- Comfort and safety of residents (Sarmadi, 2013). Generally energy management in buildings involve multi-axis: 1- Control systems for cooling, heating, ventilation 2- Control of lighting system 3- Power Quality control 4- Control the level of carbon dioxide in the building (Rezaei, Nahavandi, Zendeh Shahvar, 2013). The concept of intelligent building and the views were formed during the last two decades. The so-called intelligent building from the early 1980s have been used and from the beginning offered different definitions of intelligent building. For example Wigginton and Harris (2002) have given thirty-four definitions of intelligent building and thirteen views about smart laminated and body. These definitions can be combined to offer a simple definition of Wigginton and Harris. That posing as a variable mixes of technology, change and improve itself to comfortable conditions within the building and provide whatever is related to the external environment (Wigginton and Harris, 2002). This concept can be stated as a different view, "energy + information = less energy," ( 2012 Lawrence). The concept of building management system (BMS) has its roots in the early 80s (Sinopoli, 2010). BMS or BAS is a system that is installed in a building and make possible for the user to control different parts of the building through suitable component outputs. Different parts of control systems usually include mechanical ventilation (HVAC) equipment and lighting, which can accelerate safety systems, fire protection, set permissions, and uninterruptible power supply (Morovati et al, 2014; 3). The general objective of the BMS systems in a building is due to environmental conditions and the need to adapt the operating conditions of the various components of the building at that time. Automatic control of residential houses or office buildings, in spite of reducing the costs of energy consumption, saves time, increase security and convenience to people in their work environment. Today in the modern world the use of technology and consequently use of electric energy and other energy, has become the largest need of community, we should take steps to take advantage of the technology and also to reduce energy consumption. According to available statistics, the highest energy consumption of the transport sector belongs to residential areas. The greatest amount of energy in residential areas, after subsystems of cooling heating and air conditioning 
belongs to lighting system.

\section{OBJECTIVES OF BMS}

- Create a favorable environment for the people in the building

- Optimal use of the equipment and increase its useful life

- Provide a control system with programmable time performance

- Significantly reducing the costs associated with maintenance and optimization and energy saving

- No need for a permanent building contractor

- Monitoring and controlling of all areas under control via a pc or internet

- Having regard to the integrity of the building, all the equipment coordinates and solves interference problems and problems caused by the lack of coordination is lost.

- The possibility of taking statistical reporting of all equipment and its performance in order to optimize consumption and performance

In a smart building, in addition to the actual cost of a building, maintenance costs should be added to it. And these costs may be reduced by automatic control and communications system that will reduce costs.

Intelligent systems are installed in parallel in the house in case of failure, it does not cause any problems and in this case the clerk system can be used.

\section{ADVANTAGES OF INTELLIGENT BUILDING}

Given that the building management system increases the cost of building, saving and consumption rate can offset the initial cost. The benefit of intelligent systems is to enhance their comfort and satisfy needs. These systems can be easily controlled from around the world. In intelligent home heterogeneous systems are separated and thus there is a need for a mechanism that these systems communicate with each other. An advanced and integrated intelligent building includes the use of building technology systems. The system includes building automation, security, telecommunications, and systems of application of facility management of intelligent building. Intelligent building design and deploy the most 
cost-effective approach for building systems technology and it is a different approach to design system and hosting an important part in energy use and sustainability of buildings. Building automation systems, HVAC control, lighting control, energy management and measuring energy has specific role in determining efficiency. Smart grid is dependent on intelligent building. Smart grid balance between public use and integration of renewable energy guarantees consumption. They are sure about renewable energy sources (solar, wind) and create appropriate conditions for intelligent buildings that produce and save energy. In fact energy management is optimizing and effective use of energy.

\section{FUTURE OF INTELLIGENT BUILDING}

When transmission the environment to the building became a necessity, it is clear that the integration of digital technology to create a more sustainable life is a purpose. Research shows that the use of new technologies in the renewable energy helps to build intelligent buildings. In future, all building components are connected together, such as a computer or phone, the ultimate goal is to integrate intelligent building to intelligent global network. The following diagram illustrates the process of organizing an intelligent future.

\section{A VARIOUS SCENARIOS AND THEIR PERFORMANCE IN A SMART HOUSING}

\subsection{Bedroom Scenario}

In this part of the house just a person need to get into the bedroom and lie down in bed and sleep and by pushing a button home will be prepared, all-defined devices and belongings will be turned off so that the lights in the bedroom have low light, at the same time home alarm system will be activated and homeowners can synchronize on his personal panel check doors and windows are open or closed. Meanwhile, in the middle of the night when he wakes up and wants to go to the restroom or drink water in the kitchen, the lights turn on. When he is awake the smart system starts playing music and pulls over the curtain to see the sunrise and daylight and prepare him to a good working day and also turn on the tea maker.

\subsection{Living Room Scenario}

After a hard day of work and the subjects were to relax at home Intelligent Building 
Management System helps you again and to provide relax conditions all you need is to select a mode for lighting and enjoy it then. At the same time the ambient temperature is set and the light music starts playing and provides a relaxing environment for orders and then to reduce light curtains are closed, also touch intelligent building management system control all the amenities including TV remote, satellite, dvd, and cooler.

\subsubsection{Intelligent control of curtains}

The use of solar energy is considered in all parts of the world as a clean energy alternative to fossil fuels. The warm light of the sun as the treatment of many diseases has been of interest to researchers. Experts believe the best way to wake up is with the help of direct sunlight. Curtains intelligent control system can at any time you would like wake you up at the same time by opening the curtains quietly and start playing gentle music in the morning, slowly make you ready to wake up and enjoy a day filled with energy. Also feel free to make use of sunlight during the day, you can use the planning system to the beginning of the day and at sunset curtains open automatically be closed. Thus, the use of light and solar energy during the day, during the hours of darkness by closing curtains inside the building will be safe. Meanwhile, the curtains are open or closed at any moment, by remote control, touch panel (PDA), and handheld keys also may be embedded. It is noteworthy that apply uniform pressure and to fit the screen, makes curtains to be used for longer time and do not lose their original shape. 


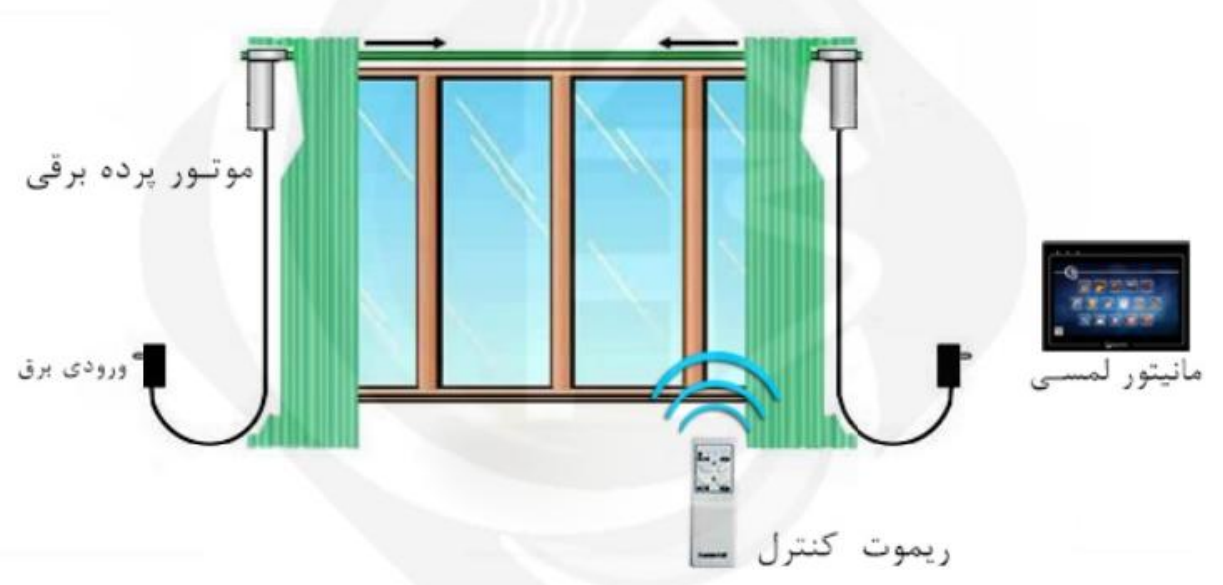

\subsection{Scenario of sports or work space at home}

Allows you to control the brightness of sports spaces (pool, sauna, jacuzzi, etc.) when entering and after exiting

Playing Music in sport space

The possibility of dimming the light at pool space

Take Control of space monitoring sports

Enable or disable the control of the unit such as: Launch sauna and Jacuzzi before returning to sport

\subsection{Kitchen scenario}

If the concentration any of toxic gas to reach more than normal, intelligent system rung alarm, cut off the gas valve entrance, call the owner's home and turn on the vents. Tea or coffee maker coincides with the arrival of the home or waking up from sleep and at the time of leaving the house all kitchen appliances turn off (except refrigerators) and there is no need to check them one by one. In addition, when people are out and forgotten food on the stove they can send a message to stove and control it. You can also watch TV program in kitchen cabinets.

\subsection{Leaving home scenario}

By pressing the button of exit out of the house all the lights and electrical appliances that are already marked, will turn off. Gas cut off and the alarm is activated and heating and cooling 
systems come in at half (to save energy). Open or closed status of the doors of the houses will be displayed on the touch screen and they can leave home without any concern about staying iron and kettle off the stove.

\subsection{The presence simulator scenario}

When the owner wants nobody find out there is no one at home, the presence simulator will be chosen to act and pull over the curtains or turn on and off the lights.

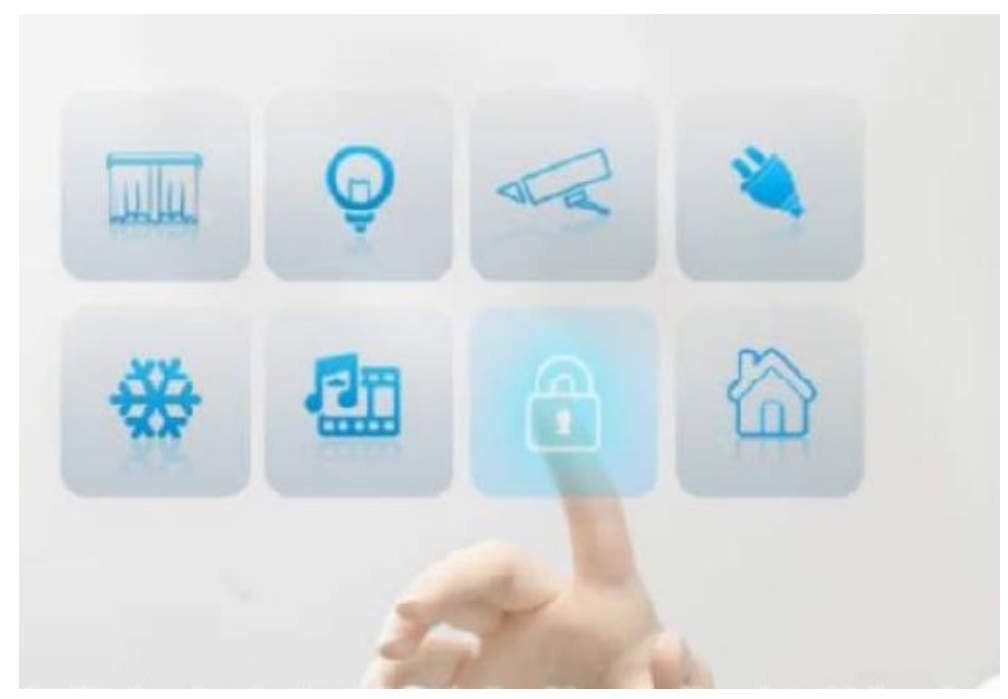

Source: Aramis Smart companies

\subsection{Entering home scenario}

Smart homeowners no longer have to use a key to enter their home. They need to just put his finger on the door lock and intelligent building systems based on fingerprints opens entrance door as well as those at home have become aware of the arrival of each member. Also with the touch of a key to the house all the systems are in a state of pre-defined, for example, disable the alarm system and lights that are defined lit. If there is light on the outside the curtains are opened and closed, if it is dark. And predetermined lamps are lit, temperature preset mode comes home and turns on the tea maker. In addition, intelligent management system provides the ambient temperature and if the person keeps a pet at home of intelligent system can automatically give them food at different distances.

\subsection{Arrival of guests' scenario}

At the moment of guests' arrival all the house lights come in preset mode, for example, decorative lights and windows are lit up to make painting and interior architecture more visible. Corridor lights and chandeliers in the reception turned on and the system will 
automatically start playing music, and heating and cooling systems as defined for the guest mode turns. At dinner time after guiding guests to the reception, all is needed is to press the button on the remote control scenario dinner. Then the lights for a romantic dinner on their light gets low and main reception area off the lights and hidden lights are lit. The heating and cooling system start working based on the specified mode (The cooling system will be turned off to avoid making food cold).

\subsection{Bath scenario}

Upon entering the bathroom without using any sensor key for the bathroom and switch detects the presence of persons and remain on as long as that person is in the bath and after leaving the bathroom lights and fans work for a certain time. Also one can use anti-fog mirror in the bathroom to watch your favorite TV program.

\subsection{Landscape Scenario}

Green space, gardens and other spaces does not need gardener and intelligent systems designated under the plan to irrigate the green spaces. The system can be programmed with drip irrigation for at the time of the specification. It also uses a rocky Loudspeaker, waterproof decorative and can be custom music with great sound and transparent echoed green space.

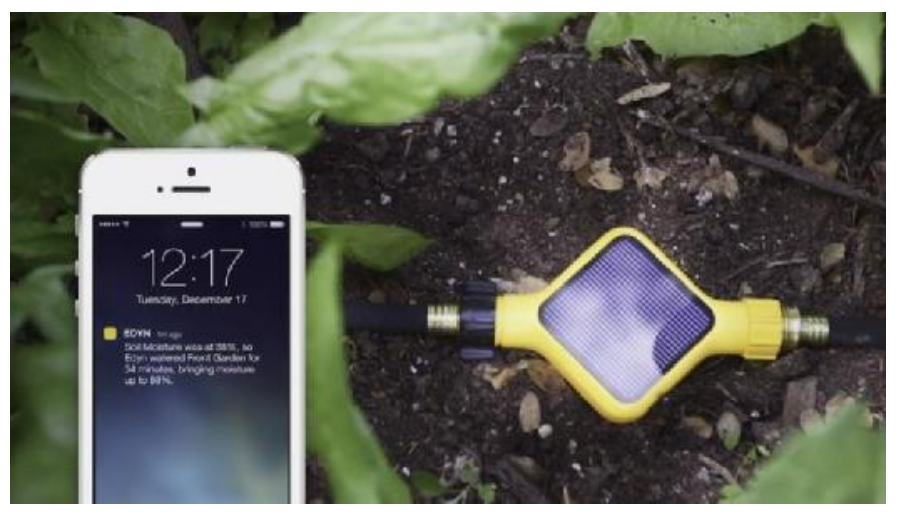

Source: http://www.bms-iran.com/

\subsection{Car parking scenario}

- Accounting and intelligent parking management and prevent the entry of unauthorized vehicles

- The possibility of receiving various reports, including the report traffic statistics cars 
- Ability to set activate lighting and ventilation systems in smart entry and exit car parking

- Making favorable security conditions for parking in the moment without the presence of the Guardian

- Signing possibility of intelligent guidance to the nearest and most appropriate place in the park

- Manage and organize incoming vehicles and the possibility of issuing a parking ticket

\section{DIFFERENT PARTS OF BMS}

\subsection{HVAC control system}

The monitoring system will display all parameters of building installation and the operator at any moment is aware of the condition of the building and as soon as technical difficulties happens it resolve that to prevent the occurrence of an event is costly.

\subsection{Engine room control system:}

The cost of the energy consumed in the Engine room (boiler chiller, AHU) and its maintenance is almost the biggest share in the cost of building, the system can be monitored and controlled in the event of a major part of the energy savings, which consequently will affect the cost of building. The installation of such a damping system installations and maintenance costs also significantly reduces mechanical equipment.

\subsection{Lighting System}

A part of the cost of electric power due to lack of clarity about the lighting in the joints of a residential office building. Due to the high number of lighting used in buildings it is proposed that all lines of lighting in the parking lot entrance lobby stairs and floors and the doors and lighting facilities are adjustable and controlled by BMS central system.

\subsection{Control and monitoring system for elevators}

Due to the high number of elevators installed in some buildings, control and monitoring by the central building management system BMS is necessary. The elevator is in what floor, what is the doors situation, if something went wrong technically and leads to stop the elevator or its door is not opening; what the problem is. 


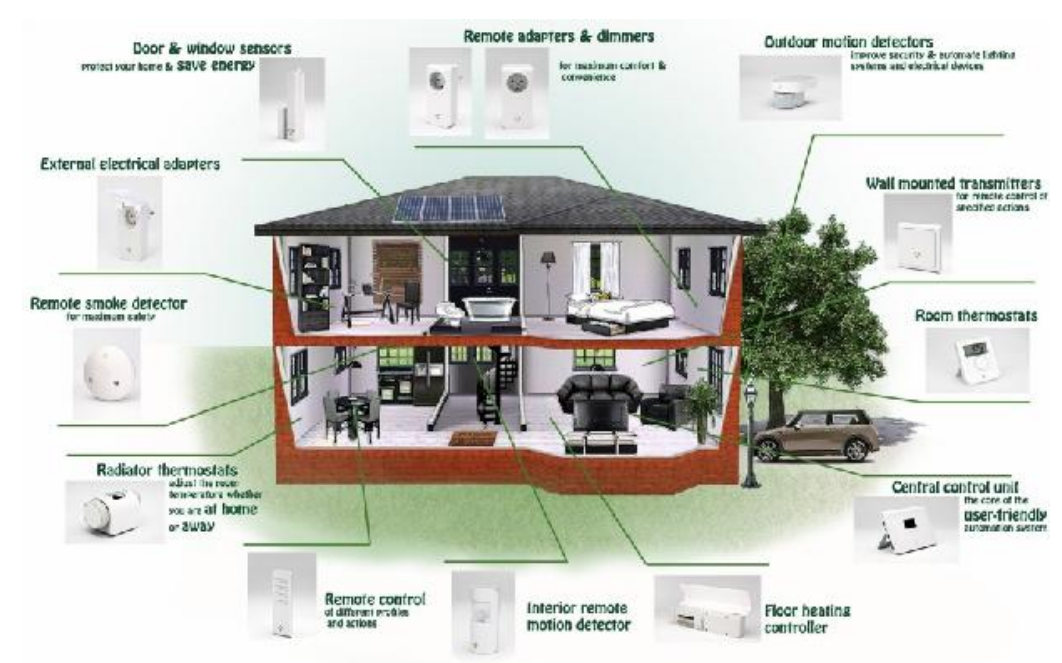

Fig.1. How to implement BMS and associated components with each other inside the building Source: http://www.bms-iran.com

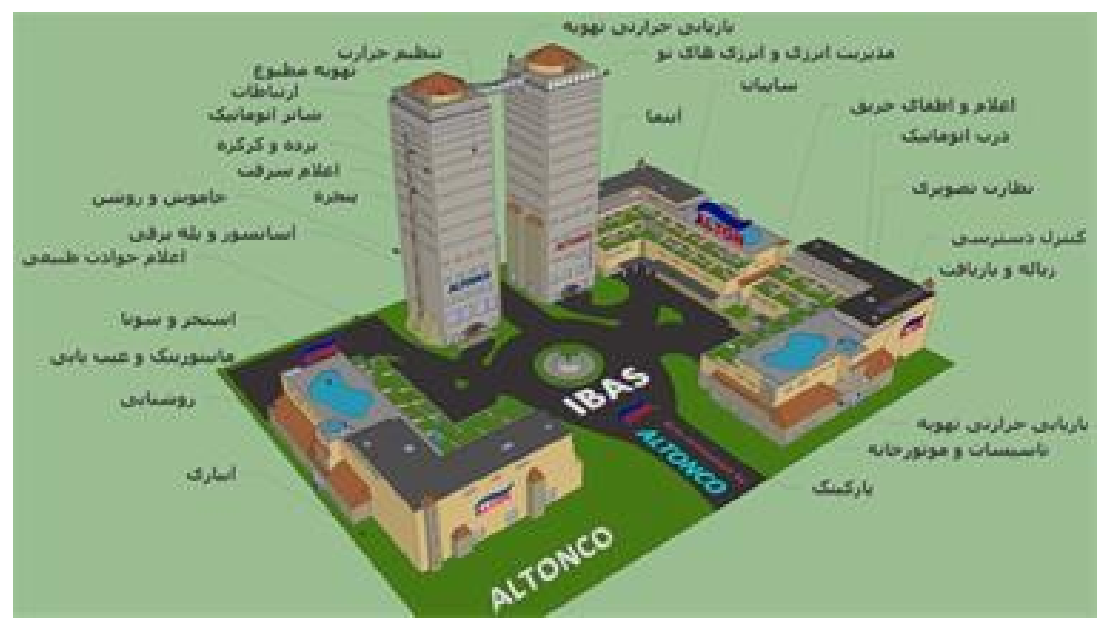

http://www.bms-iran.com/

Fig.2. How to implement BMS and components connection with each other Smart home comfortable ability to live in them and an immune system in the absence of building residents controls the conditions. These systems are separated but connected by a special mechanism for integration and have the ability to perform their joint performances. According to statistics obtained from projects based on the BMS, on average, there is about 25 to $30 \%$ reduction of the energy storage and returning the investment of the use of BMS structure is possible about 2.5 to 3 years after installing it (Jafari et al, 2011). 


\section{CONCLUSION}

This research tries to provide new ways to save energy and well-being of residents of a building, in the end it can be a smart use of smart measures in sustainable housing and introduced to the attention and show how a smart house can be effective in saving time and money. On the other hand the benefits of intelligent BMS building management system as part of the study is considered. This can be achieved that for optimum energy savings in buildings, an initial cost should be spent by the owner and then in the long run is free of charge.

\section{REFERENCES}

1- Seyedian, A; Ebrahimi ,A; Soleymani Majd, Sh, The use of smart materials in architecture of the future, a step toward sustainable architecture

2- Afshari Basir, N; Afshari Basir, M, A step toward new technology in the construction of intelligent buildings, Second International Conference on Architecture and Structural Engineering, Tehran University, 2011

3- Sarmadi, M, A Model for entry to the construction industry, clever artificial intelligence techniques using multi-criteria decision, the International Conference of Civil Engineering, Architecture and Urban Sustainable Development, 2013

4- Ahmadi Kamarposhti, A; Gholami, P; Ahmadi Kamarposhti, M, The use of new technologies and automation in intelligent buildings, the first Regional Conference on Civil Engineering, 22 April 2011

5- Design industry, M, intelligent building management systems, technical directors and executive message publication, 2010, p. 2

6- Behzadi, B Intelligent control systems in buildings, Journal of Urban Development and Architecture-Abadi, No. 42, 2004, p. 68

7- Hariri, Reza, Principles of energy efficiency in buildings, energy management period, the International Energy Research Institute of the Ministry of Oil, 2009 
8- Amirpadiab, E, Iraj, Fashions achieve stable housing by smart measures, Research Conference on Science and Technology, Berlin, Germany, 2006

9- Rezaei, D; Nahavandi, M; Zendeh Shahvar; Mohammad Amin, Provide architectural solutions to store energy in residential buildings and smart performance, the first national conference on sustainable architecture and urban space, 2013

10- Moravati, A; Bahari, T; Firouzfar, S, Explore solutions to optimize energy consumption in smart buildings, new approaches to the Third International Conference on Energy Conservation, 2014

11- Jafari, V; Tavasoli, H; Zeinali, I, Optimization of energy consumption in smart buildings, the first conference on climate, building and energy efficiency, 2011

12- M Engineering Technical Group H.

13-Sinopoli. J., Smart building systems for Architects, Owners, and Builders, ButterworthHeinemann: USA, 2010

14- Wigginton, M. and Harris, J. (2002) Intelligent Skins. Oxford: Architectural Press

15- Asdubali, Francesco, twelfth meeting of jca on ict and climate chance special focus smart sustainable cities,5, February 2013

16- Rodio, jared, the green building behind the smart building: can you have both?, 2014

17- Agent building and learning environment", http://www.alphaworks.ibm.com/tech/able

\section{How to cite this article:}

Mirpadiab S K, Bagheri S. Identifying intelligent building management systems (bms) in sustainable housing. J. Fundam. Appl. Sci., 2016, 8(3), 1175-1190. 